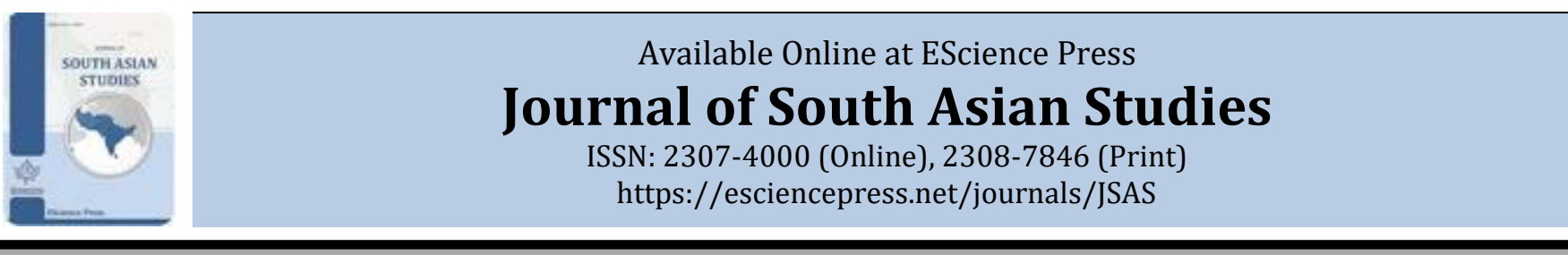

\title{
Attitudes and Behaviors of Health Care Professionals Towards Preventive Measures Against COVID-19
}

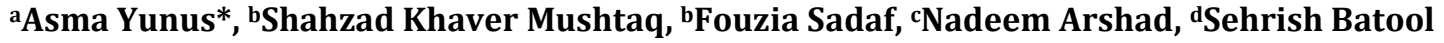 \\ a Department of Sociology \& Criminology, University of Sargodha, Sargodha, Pakistan. \\ $\mathrm{b}$ Institute of Social and Cultural Studies, University of the Punjab, Lahore, Pakistan. \\ c Food fortification officer Nutrition International, Pakistan. \\ d Cornelius Law College, Sargodha, Pakistan.
}

*Corresponding Author Email ID: asmayounus@gmail.com

\section{A B S T R A C T}

The purpose of this study is that healthcare professionals play the most significant role in tackling pandemic COVID19 and are considered as the most vulnerable and at-risk population for infection. An effective response to a pandemic depends on the attitudes and behaviors of physicians, nursing, staff, lab technicians, and other support staff. The study was conducted to explore the attitudes and behaviors of health care professionals towards preventive measures against COVID-19. The study was designed following the positivistic research paradigm hence cross-sectional survey research was selected as the most appropriate design. For the purpose of data collection, a self-administered structured questionnaire was developed and used. The survey was conducted during the month of March 2020 in Punjab through an online data collection method from 150 health care professionals working in various public sector hospitals in Punjab. The questionnaire was uploaded on the survey monkey website and shared on various social media platforms to collect data in order to get responses. Results show that self-reported anxiety level is high among physicians and nurses as compared to technical and support staff. Data shows that there are significant differences in attitudes and behaviors towards preventive measures against pandemic COVID-19 between physicians and nurses especially about the adoption of various techniques for improving immunity. It was also found that there are significant attitudinal and behavioral differences according to sex, region of residence, and marital status of health care professionals.

Keywords: Pandemic COVID-19, Anxiety, Health care professionals, Attitude, Behaviour, Immunity.

\section{INTRODUCTION}

A pandemic is a disease that has spread over a large area, for example, various central lands or around the world, influencing a considerable number of individuals (WHO, 2019). Human history has observed different pandemics, for example, smallpox and tuberculosis. One of the most annihilating pandemics was the Black Death or Plague, which caused an approximate death toll of 75-200 million people in the fourteenth century (Zietz, \& Dunkelberg, 2004). Other notable epidemics include the 1918 flu pandemic also called Spanish influenza and the 2009 flu pandemic (H1N1) (Adhikari, Meng, Wu et al., 2020). These pandemic episodes have caused both short-term and long-term physical, social, economic, and psychological effects on the human population across the world (Pfefferbam, Betty North \& Carol, 2020). Now, the world is experiencing COVID-19, which was declared Pandemic on March 11th, 2020, by WHO (WHO, 2020).

The Pandemic was initiated in Wuhan city of China, in late December 2019 and caused instances of acute respiratory disease, which is alluded to as Corona Virus disease 2019 (COVID-19) (Li, Guan,Wu, Wang, Zhou, Tong et al., 2020). As per media reports, approximately 200 states have been influenced by COVID-19, with a significant outbreak in the United States, Central China, Western Europe, and Iran. Starting on April 17th, 2020, the number of individuals affected with COVID-19 arrived at 2.25 million around the world, the mortality is 
154,295 , and the number of patients recovered is 574,383 so far (Center for Disease Control and Prevention [CDC], 2020). Primary symptoms of the disease include respiratory issues, high fever, cough, shortness and difficulty in breathing, etc. (WHO, 2020, NIH Pakistan, 2020). In extreme cases, the disease can cause pneumonia, severe acute respiratory disorder, kidney failure, and even death ( $\mathrm{Li}, \mathrm{Guan}, \mathrm{Wu}$, Wang, Zhou, Tong et al., 2020). This infection is spread through direct contact with respiratory droplets of a carrier in case of sneezing, coughing, and touching (CDC, 2020). The common preventive measures are physical distancing, respiratory hygiene, frequent hand washing, and covering your sneeze or cough with a tissue or fixed elbow along with disposal or sanitizing of fabric or infected things (WHO, NIH, CDC, UNICEF, WMHC, 2020). The first case of COVID-19 was reported in Karachi, Pakistan. Since then, locally transferred cases are raising in numbers gradually. The number of total instances till April 20t were 8418 while active cases were 6272, with a death toll of 176 (Haider, 2020). The essential measures taken by the state include the closing of the border with neighboring countries, prohibiting large gatherings, and closing of educational institutes at all levels, and a partial or complete lockdown in all provinces (Ayres \&Fliegauf, 2020). The state has set up much quarantine across all provinces to not only isolate the patients but also to be taken care of by competent health care staff (Khattak, 2020). It is a hardcore fact that Health care professionals have played a crucial role in combating viruses and saving humanity. So far COVID19 outbreaks have been experienced as "the never seen before" global dilemma in terms of its devastating and outreaching effects on the human population (CDC, 2020). Health care professionals (HCP) are on the frontline in taking care of people in a battle against this invisible enemy (WHO, 2020). One of the main concerns related to the present pandemic COVID-19 is the overwhelming burden on medical structures and resources, which poses a negative impact on HCP's mental and physical health (NIH Pakistan, 2020). Govt. of Pakistan reports that this situation puts healthcare professionals in the unusual position of being both the leading fighters and potential targets of the COVID-19, which makes them an essential vector for transmission of the Pandemic. For this reason, it is crucial to understand the behavior and attitudes of health care professionals about the spread of the Pandemic and preventive measures to stop the spread (Shereen, Khan, Kazmi, Bashir \& Siddique, 2020).

The governments across the globe currently are adopting various scientific and social approaches in understanding and responding to effectively manage the multifaceted challenges as a result of a common threat (Henrich, \& Holmes, 2010). In addition, human societies, are diversely ranked based on disparities in their economic, social, scientific, and medical achievements, it is, therefore, essentials to investigate and analyze context-specific experiences of Health Care Professionals while performing their critical role in a particular society to better understand the challenges that the risky professional duties of health workers pose for their psychological and physical health (Lakoff, 2017). Given the current circumstances, academic researchers across the globe are actively involved in exploring and explaining how the professional responsibilities of frontline workers have been influencing and shaping their personal, psychological, social, and physical wellbeing (Covello, 2003). This academic scholarship expects to offer accurate, expert-driven, and scientifically informed policies, procedures, and actions aimed to support those frontline fighters.

Thus, the study aims to analyze and reduce the risk and vulnerability attached to work in the medically stretched and underprivileged system. It explores the attitudes and behaviors towards preventive measures against Pandemic among HCP working in public sector hospitals in Punjab Province, considering the characteristics of the Pakistani health care setting. The survey was carried out by using a structured online questionnaire because of the lockdown situation during this time period.

\section{THEORETICAL FRAMEWORK}

The stress theories have been used to understand the issues of healthcare professionals in Pakistan who are currently frontline workers to deal with the COVID-19 pandemic. The prevalence and spread of pandemics have generated public stress (Nieet al., 2021) as masses are confronted by many social, physical and psychological upheaval during this phase (Lazarus, 1984). When a person experiences stress, his/her stress adaptation system is activated (Ursin and Eriksen, 2004). Some social psychological theories suggest that people in adverse situations gain information about the situation are more prone to get in stress, yet this stress may cause more preparedness to deal with the situation. Response 
to stress enables people to fight against the odds (Ursin, 2009). While stress response is essential to face challenges, higher levels of sustained stress can lead to physical and mental disorders. We argue that the sustained workload and mental stress of the healthcare professionals during the pandemic originate an acquired expectancy referred to as "hopelessness" (Erikson et al, 2005) and it leads them to acquire preventive measures for combating the COVID-19 pandemic.

\section{MATERIALS AND METHODS}

Data was collected through a self-administered structured questionnaire. The questionnaire was made available in form of Google docs and was shared personally and on various social media forums of Health care professionals and a remote recording system collected the anonymous answers given by the health care professionals $(\mathrm{n}=148)$. Along with the survey questionnaire, a consent form was made available to inform about the objectives of the study, voluntary participation, assurance of confidentiality, and privacy. The health care professionals included Physicians/Doctors, Nursing staff, technical staff, and support staff. Access to the online questionnaire was permitted from November 1 to 30, 2020 including weekends.

Table 1. Frequency and Percentage distribution of background variables while $\mathrm{N}=148$.

\begin{tabular}{ccc}
\hline Variables & Frequency(f) & Percentage(\%age) \\
\hline Sex & & 58.7 \\
\hline Male & 87 & 41.3 \\
\hline Female & 61 & 25.0 \\
\hline Occupation & 37 & 25.0 \\
\hline Physician & 37 & 25.0 \\
\hline Nursing Staff & 37 & 25.0 \\
\hline Technician & 37 & 36.83 \\
\hline Support staff & & 63.17 \\
\hline Marital Status & 55 & \\
\hline Single & 93 & 62.24 \\
\hline Married & & 37.76 \\
\hline Under 16 Children & 92 & 65.9 \\
\hline Yes & 56 & 34.1 \\
\hline No & & 20.5 \\
\hline Have +70 years person at home & 98 & 79.5 \\
\hline Yes & 50 & \\
\hline No & & 45.27 \\
\hline Hes & 30 & 54.73
\end{tabular}

Source: Primary data collected for this study.

Table 1 is about the frequency and percentage of socio demographic variables. It depicts that majority 38.51 percent of respondents belong to age group 30-49 second majority 29.73 percent respondents belongs to age group 50-64 while 25.68 percent respondents belong to age group $18-29$ only 6.08 percent respondents were 65 or above. Out of 148 respondents, 58.7 percent were male while 41.3 percent were female.
Respondents belonged to 8 different districts of Punjab, i.e., from Hafizabad (9.46), Gujrat (17.57 percent), Lahore (20.27 percent), M.B. Din (5.41 percent), Rawalpindi (15.54 percent), Gujranwala (12.16 percent), Multan (14.19 percent) and Khaniwal (5.41 percent). Occupation-wise division of the respondents is Doctors/ Physicians (25 percent), Nursing staff (25 percent), Technicians ( 25 percent), and Support staff ( 25 percent). 
From them 25 percent of respondents were MBBS, 30.41 percent had nursing degrees, while 34.46 percent of respondents have a Diploma in OT or Lab Tec. And 10.14 percent were pharmacists. 63 percent of respondents were married, and 36.83 percent respondents were unmarried. Of them, 62.24 percent of respondents have under 18 children at their homes, while 37.76 percent respondents don't have under 18 children at their homes. While 65.9 percent of respondents had no old age person at their homes, 34.1 percent had no old age person at their homes. Similarly, 20.5 percent of respondents had a person with serious illness at their home while the majority 79.5 percent had not. The perceived health status of respondents was 54.5 percent excellent, 36.2 percent good, 8.4 percent fair, and 0.9 percent poor, from the 67 (45.27 percent) who were in direct with COVID-19 patients and 81 (54.73 percent) and not in direct contact with COVID-19 patients.

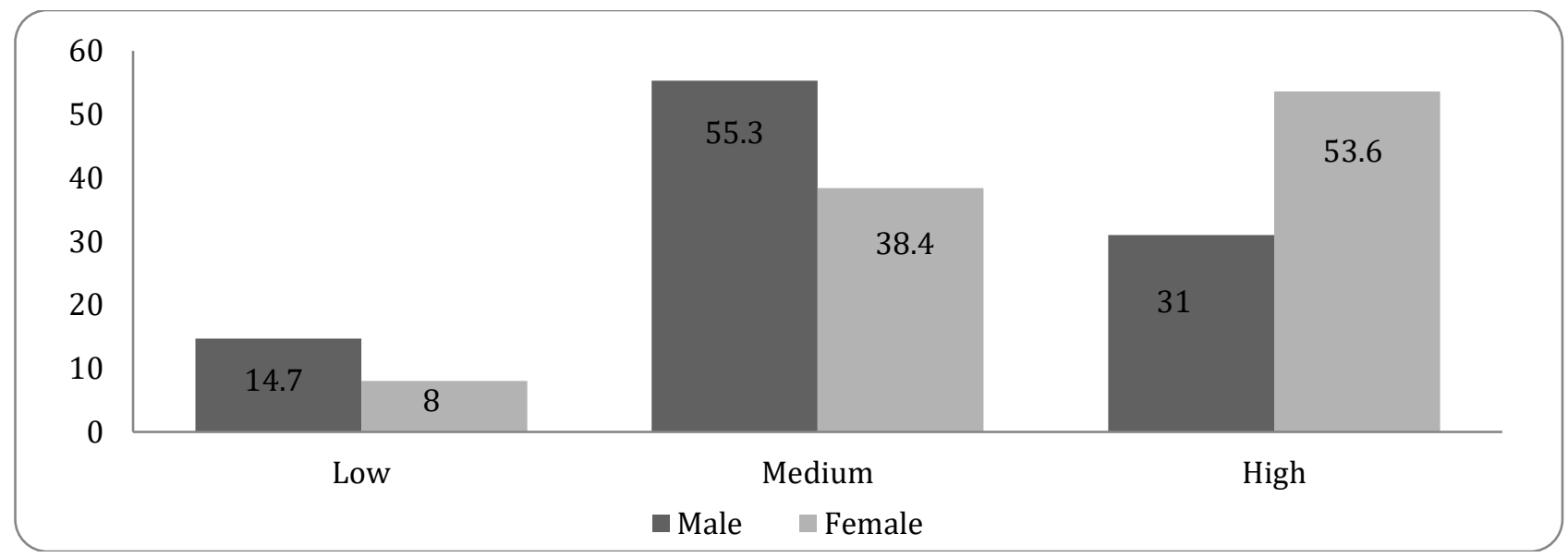

Figure 1. Level of anxiety among male and female HCP.

Source: Primary data of the study.

Figure no 1 is about the level of anxiety among male and female in the wake of COVID-19. Findings of the table reveal that 53.6 percent women reported that they are experiencing higher level of anxiety as compared to 31.0 percent mal which is almost half than females, on the other hand majority 55.3 percent male reported they are experiencing medium level of anxiety while smaller number of women than men i.e., 38.4 percent reported medium level of anxiety, and only 8 percent women reported that they are experiencing low level of anxiety as compared to 14.7 percent male. The level of anxiety is higher in female as compared to male health professionals.

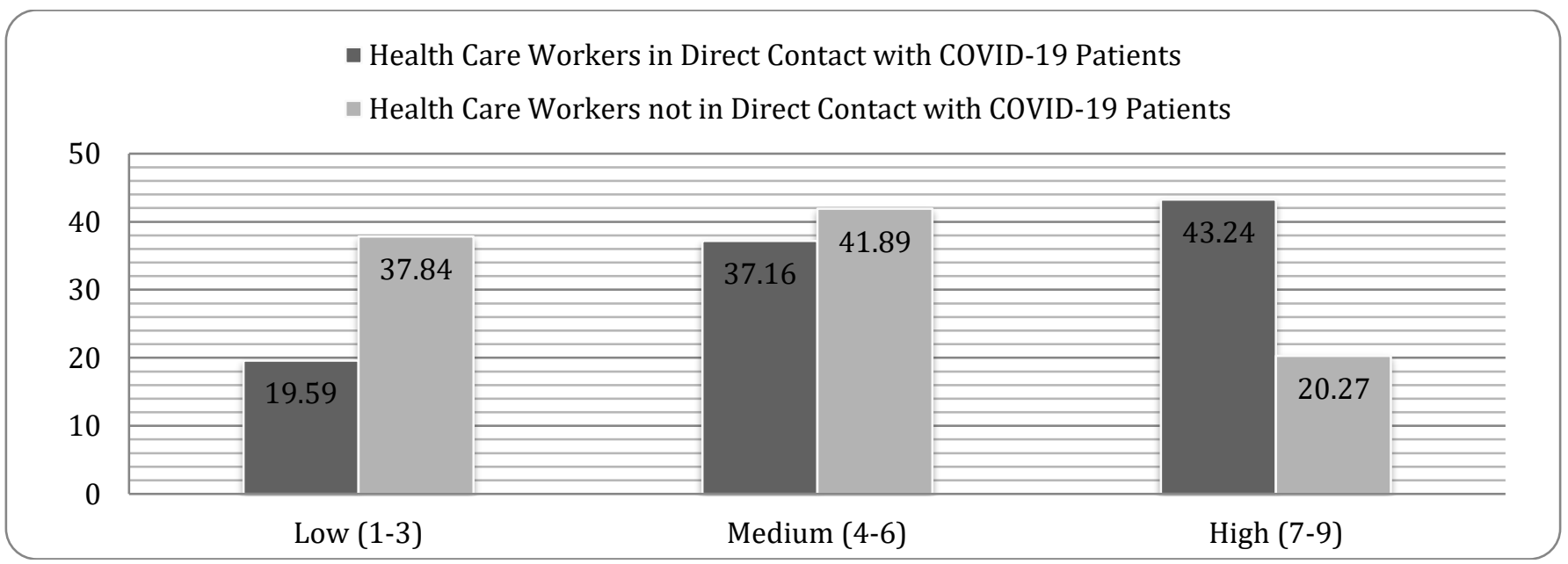

Figure 2.Difference in Level of anxiety among Respondents who are/not in Direct contact with COVID -19 patient. Source:The primary data of this study. 
Figure no. 2 explains differences in level of anxiety among Health care professionals who are dealing CVID19 patients directly or indirectly. The table divides the respondents in three categories of Low Medium and High. Low and Medium Categories show a slightly higher anxiety level among workers who are not directly dealing with the COVID-19 patients while in higher anxiety category, Health care professionals in direct contact has a higher percentage 43.24 percent as compared to 20.27 percent.

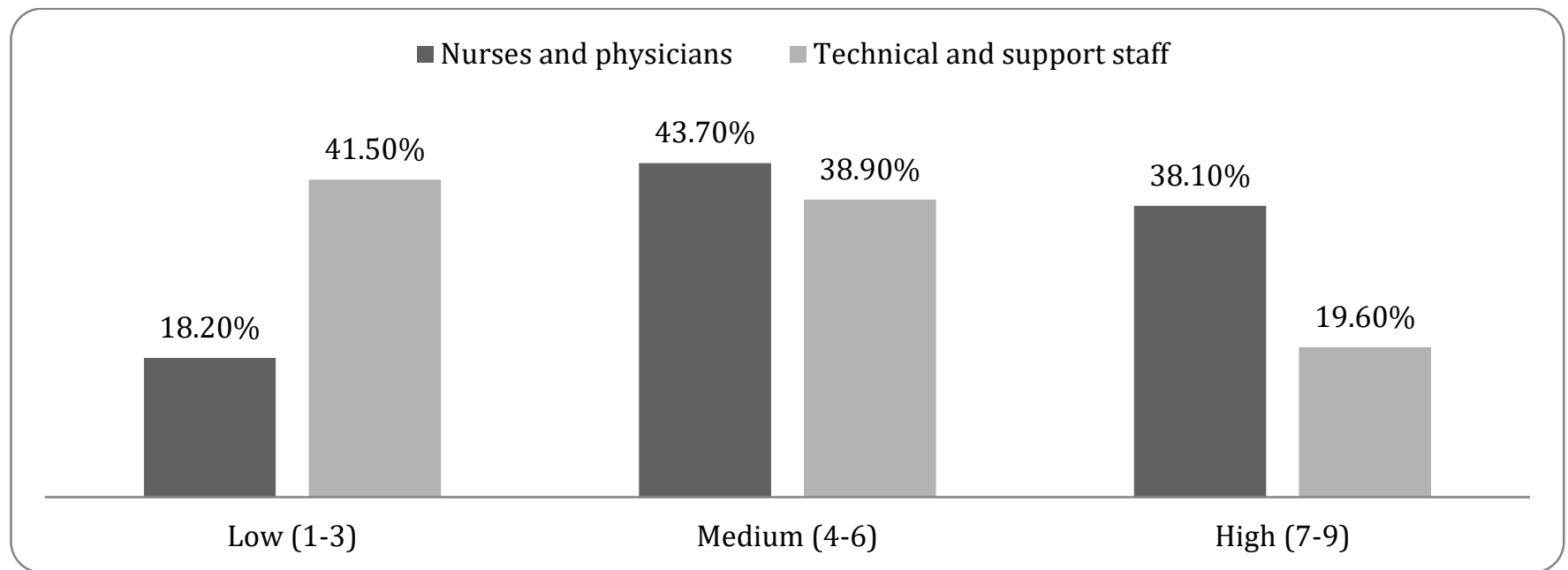

Figure 3. Level of anxiety among Nurses, Physicians and Technical staff.

Source:Primary data of the research.

Figure no. 3 compares the level of anxiety reported by Nurses, Physicians and Technical \& support staff. The table reveal that Majority 38.10 percent. Nurses and Physicians experiencing high level of anxiety with comparison of 19.60 percent, technical and support staff, similarly 43.70 percent. Nurses and physicians experience medium level of anxiety with comparison of 38.90 percent.Technical and support staff while only 18.20 percent. Nurses and Physicians experience low level of anxiety as compared to $41.50 \%$ Technical and support staff. Through this table it can be concluded that Nurses and Physicians experiencing higher level of anxiety working in the wake of COVID-19 as compared to technical and support staff.

Figure no. 4 (see next page) enlists preventive measures adopted during duty by physicians/nurses and Technical/helping staff. The data reveals that 73.50 percent of doctors and nurses wash and sanitize their hands during duty as compared to 35.70 percent technical and helping staff while 17.40 percent of doctors and nurses sometimes wash and sanitize their hands during duty as compared to 38.30 percent technical and helping staff and only 9.10 percent doctors and nurses never wash and sanitize their hands during duty as compared to 26 percent technical and helping staff. On the other hand, majority 38.30 percent technical/helping staff sometimes washes and sanitizes their hands during duty as compared to 17.40 percent of nursing/physicians, while 26 percent of technicians and helping staff never washed and sanitize their hands as compared only least number of doctors and nursing staff which is 17.40 percent in the wake of COVID-19. Secondly during duty, a significant majority 63.50 percent Physicians/Nurses used masks as compared to 32.40 percent technical/helping staff, while 38.90 percent technical/support staff use masks sometimes as compared to 22.40 percent Physicians/Nurses and only 14.10 percent of Physicians/Nurses never use a mask during duty as compared to 28.70 percent Technical/Support staff. The use of preventive kit to COVID-19 use is higher in physicians/Nurses as compared to technical/support staff as data reveal that 48.70 percent of Physicians/Nurses always used the preventive kit to COVID-19 as compared to 12.56 percent Technical/Support staff, while 23.90 percent physicians/nurses used preventive kit sometime as compared to 21.30 percent technical/support staff only 27.40 percent physicians/nursing staff never used the preventive kit as compared to a note able majority of technical/support staff which is 66.14 percent. 
Social/Physical distancing among physicians is higher than the technical/support staff as data depicted that the majority of the physicians/nurses 59.23 percent maintain social/physical distance as compared to 26.40 percent technical/support staff, while 30.30 percent of physicians sometimes maintain physical distance during duty as compared to 43.20 percent technical/support staff and only 10.47 percent physicians never maintain social/physical distancing during duty with the comparison of 30.40 percent technical/support staff.

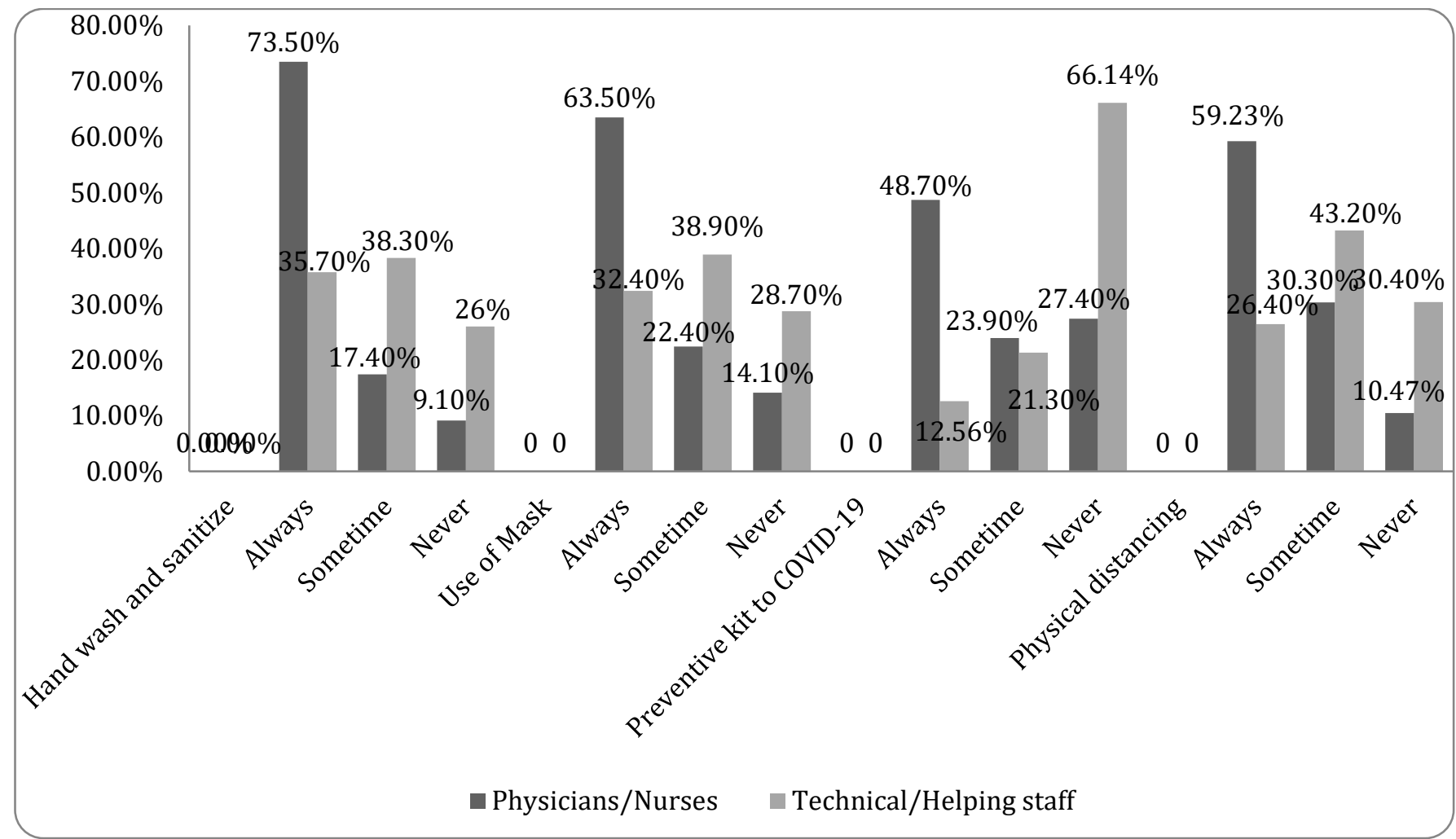

Figure 4. Preventive measures taken during duty.

Source: Primary data of the research.

Table 2. Distribution of HCP according to their practices at home while N=148.

\begin{tabular}{|c|c|c|c|c|c|c|c|c|}
\hline \multirow[t]{2}{*}{ Preventive measures } & \multicolumn{2}{|c|}{ Most of the time } & \multicolumn{2}{|c|}{ Sometime } & \multicolumn{2}{|c|}{ Almost never } & \multicolumn{2}{|c|}{ Score } \\
\hline & 1 & 2 & 1 & 2 & 1 & 2 & 1 & 2 \\
\hline Wash/ Sanitize hands & $94.09 \%$ & $43.80 \%$ & $4.32 \%$ & $36.40 \%$ & $1.68 \%$ & $19.80 \%$ & $97.44 \%$ & $74.67 \%$ \\
\hline Change cloth & $63.40 \%$ & $38.43 \%$ & $18.27 \%$ & $42.50 \%$ & $18.33 \%$ & $19.07 \%$ & $81.69 \%$ & $73.12 \%$ \\
\hline Self-isolation at home & $34.90 \%$ & $13.43 \%$ & $47.73 \%$ & $41.20 \%$ & $17.37 \%$ & $45.37 \%$ & $72.51 \%$ & $56.02 \%$ \\
\hline Food sharing & $3.88 \%$ & $24.14 \%$ & $12.40 \%$ & $28.34 \%$ & $83.72 \%$ & $47.52 \%$ & & \\
\hline $\begin{array}{l}\text { Main Distance from } \\
\text { vulnerable/at risk people }\end{array}$ & $51.43 \%$ & $32.72 \%$ & $30.50 \%$ & $41.20 \%$ & $18.07 \%$ & $26.08 \%$ & $77.79 \%$ & $68.88 \%$ \\
\hline $\begin{array}{l}\text { Washing of fruit/ } \\
\text { vegetable/groceries when } \\
\text { you bring it home }\end{array}$ & $82.70 \%$ & $76.87 \%$ & $12.63 \%$ & $14.20 \%$ & $4.67 \%$ & $8.93 \%$ & $92.68 \%$ & $89.31 \%$ \\
\hline Disinfect car keys, shoes et & $17.23 \%$ & $13.35 \%$ & $10 \%$ & 88120 & 41370 & & 50620 & 5161 \\
\hline
\end{tabular}

Source: Primary data of the study

1. HCP having vulnerable/ at risk person at home

2. HCP have not vulnerable/ at risk person at home

Table 2 depicts the practices of HCP at home when they

return from duty. The table reveals that a significant 
majority 94.09 percent having vulnerable people at their home always wash/sanitize their hands when they returned from duty as compared to 43.80 percent have not vulnerable person at their home, 4.32 percent of HCP having vulnerable/at-risk person at their home sometime wash their hands when they returned from duty as compared to 36.40 percent don't have a vulnerable person at their home while there are only 1.68 percent HCP having vulnerable person at their home don't wash/sanitize their when they returned from duty as compared to 19.80 percent don't have a vulnerable person at their home.

After returning from duty majority i.e. 63.40 percent HCP having the vulnerable person at their home change their clothes as compared to 43.80 percent don't have the vulnerable person at their home, similarly only a few i.e. 18.27 percent having the vulnerable person at their home change their clothes sometimes as compared to 42.50 percent HCP don't have the vulnerable person at their home and the almost same number of HCP 18.33 percent never change their clothes as they returned from duty while 19.07 HCP don't have the vulnerable person at their home never change their clothes. Overall score illustrates that HCP having the vulnerable person at their home change cloth as preventive measurement as they returned from duty as compared to those who haven't the vulnerable person at their home.

Self-isolation is one of the most effective preventive techniques against COVID-19. Table data reveals that 34.90 percent HCP having the vulnerable person at their homes keep themselves isolated when they are at home as compared to 13.43 percent don't have the vulnerable person at their home, majority i.e. 47.73 percent HCP having the vulnerable person at their home sometimes keep themselves in isolation at home as compared to 41.20 percent don't have the vulnerable person at their home while only 17.37 percent HCP having the vulnerable person at their home never keep themselves at their home as compared to a note able majority 45.37 percent haven't vulnerable person at their home. Overall data score depicts that self-isolation is higher in HCP having the vulnerable persons at their home as compared to HCP haven't vulnerable persons at their home. In response to food sharing a significant majority,
83.72 percent having vulnerable/at-risk person at their home don't share food with other family members as compared to 47.52 percent haven't vulnerable person at their home, while only 12.40 percent have the vulnerable person at their home sometime shared their food with family members as compared to 28.34 percent haven't vulnerable person at their home, while only 3.88 percent HCP having the vulnerable person at their home always shared their food with family members as compared to 24.14 haven't vulnerable/ at the high-risk person at their home.

Significant majority 51.43 percent having vulnerable/atrisk person at their home maintain distance from them as preventive measurement as compared to 32.72 percent haven't vulnerable person at their home, while 30.50 percent having vulnerable persons at their home maintain distance sometimes as compared to 41.20 percent don't have vulnerable persons at their home, and only 26.08 percent HCP having the vulnerable person at their home never maintain distance as compared to 26.08 percent don't have a vulnerable person at their home. Overall scores which are 77.79 percent for HCP having the vulnerable person at home and 68.88 percent don't have the vulnerable person at their home shows that the practice of maintaining distance is higher among HCP having the vulnerable person at their home than the HCP having not. The practice of washing fruit/vegetable/groceries when HCP brings it at home is almost the same among both populations i.e., HCP has vulnerable/ at-risk person at home and HCP have not vulnerable/ at-risk person at home as data shows that 82.70 percent of HCP having the vulnerable person at their home always washed, 12.63 percent some time and 4.67 percent never, while among HCP don't have vulnerable persons at their home washed fruits and vegetables 76.87 percent always, 14.20 percent some time and 8.93 percent never. While only 17.23 percent HCP having the vulnerable person at their home disinfect car keys, shoes, etc. always, 41.40 percent some time and almost same 41.37 percent never, as compared to HCP having not the vulnerable person at their home 13.35 percent always, 28.12 percent some time, 58.62 percent ever disinfect car/bike keys and shoes. 
Table 3.Showing the habits to promote immunity.

\begin{tabular}{ccccccc}
\hline \multirow{2}{*}{ Measures } & \multicolumn{3}{c}{ Physicians/ Nurses } & \multicolumn{2}{c}{ Technical and helping staff } \\
\cline { 2 - 6 } & Always & Sometimes & Never & Always & Sometimes & Never \\
\hline Taking healthy diet & $76.17 \%$ & $14.20 \%$ & $9.63 \%$ & $43.61 \%$ & $28.74 \%$ & $27.65 \%$ \\
\hline Taking dietary supplements & $31.41 \%$ & $39.90 \%$ & $28.96 \%$ & $12.74 \%$ & $24.27 \%$ & $62.99 \%$ \\
\hline Taking exercise & $23.17 \%$ & $32.90 \%$ & $43.93 \%$ & $13.60 \%$ & $16.32 \%$ & $70.08 \%$ \\
\hline $\begin{array}{c}\text { Consuming more liquid } \\
\text { (Water, Juice and Citrus }\end{array}$ & $68.0 \%$ & $22.04 \%$ & $9.96 \%$ & $34.91 \%$ & $37.12 \%$ & $27.97 \%$ \\
\hline Take 8 to 10 hour of good sleep & $68.12 \%$ & $12.40 \%$ & $19.48 \%$ & $63.15 \%$ & $12.40 \%$ & $24.45 \%$ \\
\hline
\end{tabular}

Source: Primary data of the study.

Table no. 3 describes healthy habits to enhance immunity to avoid COVID-19. This table provides the difference between two groups i.e., Physicians/Nurses and Technical and helping staff. The finding of the table shows that a significant majority 76.17 percent of the physicians/Nurses take a healthy diet most of the time and 14.20 percent take a healthy diet sometimes while only 9.63 percent almost never take healthy diet, while the practice of taking healthy diet among technical/Helping staff lower than physicians/Nurses which is 43.61 percent took healthy diet most of the time, while 28.74 percent took healthy diet sometimes and almost same 27.65 percent almost never took healthy diet. Taking dietary supplements is also higher in doctors to enhance immunity 31.41 percent of doctors take dietary supplements most of the time, while the majority 39.90 percent take dietary supplements sometimes and 28.96 percent almost never take dietary supplements. In contrast use of dietary supplements among technical/helping staff is less than doctors/nurses which is only 12.74 percent take dietary supplements most of the time, 24.27 percent take dietary supplements sometimes and a significant majority i.e., 62.99 percent almost never takes dietary supplements.

There is a slight difference in taking exercise between physicians/nurses and technical/helping staff. 23.17 percent of physicians/nurses take exercise most of the time, 32.90 percent take exercise sometimes and the majority i.e., 43.93 percent almost never take exercise. While only 13.60 percent of technical/support staff take exercise most of the time, 16.32 percent take exercise sometimes, and the majority i.e., 70.08 percent almost never take exercise. Consuming more water, juice, and citrus is one of the best ways to enhance immunity against COVID-19. A significant majority 68.0 percent doctors/nurses consumed more, water, juice, citrus, and fruits to enhance immunity, in contrast only 34.91 percent of technical/helping staff consume more liquid, water, juice, citrus, and fruits, similarly, 22.04 percent of doctors/nurses consume more liquid and fruits in comparison of 37.12 percent technical and helping staff, while only 9.96 percent doctors/nurses almost never consume more liquid, citrus, and fruits in comparison of 27.97 percent technical/support staff. On the basis of data, it can be concluded that consumption of liquid, fruit, citrus is higher among doctors/nurses as compared to technical/helping staff. Both physicians/nurses and technical/helping staff almost take equally proper 8 to 10-hour sleep to enhance immunity. 68.12 percent of doctors/nurses take always good sleep 8 to 10 hours in comparison of technical/helping staff which is 63.15 percent while only 12.40 percent doctors/nurses sometimes take proper 8 to 10 -hour sleep as compared to same 12.40 percent technical/helping staff and 19.48 percent doctors/nurses almost never take proper sleep, in comparison with 24.45 percent technical/helping staff.

\section{CONCLUSION AND RECOMMENDATIONS}

Results show that self-reported anxiety level is high among physicians and nurses as compared to technical and support staff. Data shows that there are significant differences in attitudes and behaviors towards preventive measures against pandemic COVID-19 between physicians and nurses especially about the adoption of various techniques for improving immunity. It was also found that there are significant attitudinal and behavioral differences according to sex, region of residence, and marital status of Health care professionals. The findings of the study suggest that HCP working in public institutions are vigilant in spite of being under sheer stress. As a response to their stress, they adopt more preventive measures. It is recommended for upcoming researchers to find out the predictors of trust for public health service-providing institutes to help restore the Conviction in public services institutions. 


\section{CONTRIBUTIONS}

The principal author conceived of the idea for this study, conducted an initial literature review and developed a questionnaire, wrote the draft of the manuscript, and incorporated contributions from all the other authors. SKM completed the literature searches, pretested, and finalized the questionnaire after ensuring reliability and validity. NA uploaded the questionnaire, collected it, and performed the statistical analysis. FS interpreted the data and wrote a discussion.SB arranged the references and in-text citations of the paper. All authors commented on drafts of the paper and approved the final manuscript.

\section{REFERENCES}

Adhikari, S., Meng, S., Wu, Y. et al (2020). Epidemiology, causes, clinical manifestation and diagnosis, prevention, and control of coronavirus disease (COVID-19) during the early outbreak period: a scoping review. Infect Dis Poverty 9, 29 (2020). https://doi.org/10.1186/s40249-020-00646-x.

Adnan Shereen, M., Khan, S., Kazmi, A., Bashir, N., \& Siddique, R. (2020). COVID-19 infection: origin, transmission, and characteristics of human coronaviruses. Journal of Advanced Research. doi: 10.1016/j.jare.2020.03.005.

Center for Disease Control and Prevention [CDC] (2020). "Coronavirus Disease 2020: Interim guidance for COVID-19". https://www.cdc.gov/coronavirus/2019$\underline{\mathrm{nCoV} / \text { summary.html. }}$

Covello, V. T. (2003). Best practices in public health risk and crisis communication. Journal of Health Communication, 8(3, Suppl. 1), 5-8.

Eriksen, H. R., Murison, R., Pensgaard, A. M., \& Ursin, H. (2005). Cognitive activation theory of stress (CATS): from fish brains to the Olympics. Psychoneuroendocrinology, 30(10), 933-938.

Govt. Pakistan Muslim Aid UNICEF (2020). "Corona Virus Public Awareness Campaign Sources". Muslim Aid https://reliefweb.int/report/pakistan/coronavirus-public-awareness-campaign.

Henrich, N., \& Holmes, B. (2010). Communicating During a Pandemic. Health Promotion Practice,
12(4), 610-619.

doi:10.1177/1524839910363536.

Lakoff (2017), Unprepared: Global Health in a Time of Emergency. Oakland, University of California press.

Lazarus, R. S., \& Folkman, S. (1984). Stress, appraisal, and coping. Springer publishing company.

Li Q, Guan X, Wu P, Wang X, Zhou L, Tong Y, et al (2020). Early transmission dynamics in Wuhan, China, of novel coronavirus-infected pneumonia. The New England Journal of Medicine, 382, 1199-1207.

https://doi.org/10.1056/NEJMoa2001316.

National Institute of Health (NIH), Pakistan. 2020. "Coronavirus (COVID-19), 2020".

Nie, X., Feng, K., Wang, S., \& Li, Y. (2021). Factors influencing public panic during the COVID-19 pandemic. Frontiers in Psychology, 12.

Pfefferbaum, B., \& North, C. S. (2020). Mental health and the Covid-19 pandemic. New England Journal of Medicine, 383(6), 510-512.

Ursin, H. (2009). The development of a Cognitive Activation Theory of Stress: From limbic structures to behavioral medicine. Scandinavian journal of psychology, 50(6), 639-644.

Ursin, H., \&Eriksen, H. R. (2004). The cognitive activation theory of stress. Psychoneuroendocrinology, 29(5), 567-592.

WHO, (2019) Coronavirus disease 2019 (COVID-19) Situation Report - 94, Data as received by WHO from national authorities by 10:00 CEST, 23 April 2020 ?

https://www.who.int/docs/defaultsource/coronaviruse/situationreports/20200423-sitrep-94-covid-19.pdf.

WHO, (2020) Novel Coronavirus?https://www.who.int/csr/don/12january-2020-novel-coronavirus-china/en/.

World Health Organization. WHO report: Novel Coronavirus(2019-nCoV) Situation Report-9; 29 Jan 2020?https://www.who.int/docs/defaultsource/coronaviruse/situationreports/20200129-sitrep-9-ncov.pdf.

Zietz, B. P., \& Dunkelberg, H. (2004). The history of the plague and the research on the causative agent Yersinia pestis. International journal of hygiene and environmental health, 207(2), 165-178. 
Publisher's note: EScience Press remains neutral with regard to jurisdictional claims in published maps and institutional affiliations. (c) (i)

Open Access This article is licensed under a Creative Commons Attribution 4.0 International License, which permits use, sharing, adaptation, distribution and reproduction in any medium or format, as long as you give appropriate credit to the original author(s) and the source, provide a link to the Creative Commons license and indicate if changes were made. The images or other third-party material in this article are included in the article's Creative Commons license, unless indicated otherwise in a credit line to the material. If material is not included in the article's Creative Commons license and your intended use is not permitted by statutory regulation or exceeds the permitted use, you will need to obtain permission directly from the copyright holder. To view a copy of this license, visit http://creativecommons.org/licenses/by/4.0/.

(C) The Author(s) 2021. 